\title{
Panorama do Uso Público em Parques Estaduais do Rio Grande do Sul
}

\section{An overview on Public Use in State Parks of Rio Grande do Sul (Brazil)}

Izadora Flores Rech, Luís Fernando Carvalho Perello, Celson Roberto Canto-Silva

RESUMO: O uso público de uma área protegida está associado ao processo de visitação que pode se manifestar em atividades educativas, de lazer, recreativas e de interpretação ambiental, desde que não afetem negativamente os objetivos de conservação da área visitada. No Rio Grande do Sul mais da metade das 23 Unidades de Conservação (UC) estaduais são Parques, categoria que privilegia o uso público. O Programa de Uso Público visa ordenar a presença humana no interior da UC, prevendo turismo, educação e interpretação ambiental. Este trabalho teve por objetivo diagnosticar a realidade dos programas de uso público dos parques estaduais do Rio Grande do Sul, conhecendo a percepção dos gestores dessas áreas quanto às atividades desenvolvidas e a eficácia de cada programa. Oito parques estaduais que já contam com plano de manejo foram estudados. A falta de funcionários é apontada por todos os gestores como sendo o fator responsável pelo fato de sete parques estaduais não receberem visitantes. Mais da metade das ações propostas nos programas de uso público não estavam efetivadas quando da realização do estudo.

PALAVRAS-CHAVE: Ecoturismo; Visitação; Unidades de Conservação.

\section{ABSTRACT}

The public use of a protected area is associated to the process of visitation that can manifest itself in educational, leisure, recreational and environmental interpretation activities, as long as it does not negatively affect the conservation objectives of the visited area. In Rio Grande do Sul, more than half of the 23 protected areas are Parks, a category that favors public use. The Public Use Program aims to order the human presence inside the protected area, providing for tourism, education and environmental interpretation. This study aimed to diagnose the reality of the public use programs of the state parks of Rio Grande do Sul, knowing the perception of the managers of these areas as to the activities developed and the effectiveness of each program. Eight state parks that already have a management plan were studied. The lack of employees is pointed out by all managers as being the factor responsible for the fact that seven state parks do not receive visitors. More than half of the actions proposed in public use programs were not implemented at the time of the study.

KEYWORDS: Ecotourism; Visitation; Protected Area. 


\section{Introdução}

O uso público de uma área protegida é o conjunto das atividades relacionadas à presença de visitantes cujo propósito é o de conhecer e desfrutar dos valores dos ambientes naturais garantindo, no entanto, que a presença humana não afete negativamente os objetivos de conservação da área visitada (TACÓN; FIRMANI, 2004). A definição de uso público, portanto, está associada ao processo de visitação que, por sua vez, pode estar vinculado às atividades educativas, de lazer, esportivas, recreativas, científicas e de interpretação ambiental (MMA, 2004).

A partir da Lei Federal no 9.985, de 18 de julho de 2000 (BRASIL, 2000), que criou no país o Sistema Nacional de Unidades de Conservação (SNUC), a visitação nas unidades de conservação (UC) vem sendo estimulada e divulgada (MMA, 2006; MTUR, 2010; MMA, 2011a; MTUR, 2011; MEDEIROS et al., 2011). Publicações oficiais dos setores de meio ambiente e turismo reconhecem que sem o conhecimento e apreciação por parte de visitantes e moradores do entorno, dificilmente estas áreas alcançarão seus objetivos de conservação. A visitação quando bem planejada consegue despertar na sociedade a consciência sobre a importância da conservação da natureza, podendo ainda desenvolver as economias locais e gerar recursos para o uso público da própria UC (SECRETARIAT OF THE CONVENTION ON BIOLOGICAL DIVERSITY, 2004; MMA, 2011b).

Entretanto, apesar da diversidade sociocultural, da riqueza de espécies e de ambientes próprios para a prática de ecoturismo, excluindo-se poucas exceções, as UC no Brasil ainda não são destinos consagrados de visitação. Em 2016, os parques nacionais brasileiros (categoria II da International Union for Conservation Nature - IUCN) receberam pouco mais de sete milhões de visitantes, porém apenas dois deles (Tijuca e Iguaçu) atraíram $61 \%$ deste total (ICMBIO, 2017). É preciso considerar, no entanto, que o parque da Tijuca, localizado no Rio de Janeiro, abriga a estátua do Cristo Redentor (considerada uma das sete maravilhas do mundo moderno) e possui inúmeras facilidades de acesso (FREITAS et. al., 2002; ICMBIO, $\mathrm{s} / \mathrm{d}$ ) e Iguaçu conta com uma das mais espetaculares cataratas do mundo e, ao longo do tempo, desenvolveu estruturas e diversos serviços de apoio ao turismo não somente no interior como no entorno da UC (ICMBIO, 2008). Quando se trata de parques estaduais, os poucos dados existentes também revelam um potencial de visitação ainda a ser explorado (MMA, 2004; INSTITUTO SEMEIA, 2015; PIRES; FARIA, 2015).

Com exceção das categorias la e lb (Reserva Natural Estrita e Área de Vida Selvagem), todas as demais definidas pela IUCN permitem e estimulam a prática do turismo e da recreação (EAGLES et al., 2002; OLSDER; VAN DER DONK, 2006). No Brasil, excluindo-se as Estações Ecológicas e as Reservas Biológicas (categoria la), onde é vedada a visitação, as outras três de proteção integral (Parques, Monumentos Naturais e Refúgios da Vida Silvestre) e todas as categorias de uso sustentável admitem o uso público com fins de educação ou lazer. Para 
tanto, é exigido apenas que a presença dos visitantes esteja prevista e regulada no Plano de Manejo.

No Brasil, as unidades de conservação da categoria Parque Nacional - juntamente com as Áreas de Proteção Ambiental (APAs) - que são de uso sustentável - são as que possuem maior representatividade em extensão territorial (MMA, 2011b). No caso dos parques nacionais, a lei do SNUC ao conceituar esta categoria, inclusive destaca que se trata de um espaço dedicado ao "desenvolvimento de atividades de educação e interpretação ambiental, de recreação em contato com a natureza e de turismo ecológico", oferecendo assim uma variedade de oportunidades de experiências que privilegiam o contato do visitante com os ambientes naturais (MMA, 2004; INSTITUTO SEMEIA, 2012). Para isso, cabe aos programas de uso público dos planos de manejo ordenar o turismo no interior das UC. O objetivo dos programas é o de promover o conhecimento sobre os ecossistemas e propiciar o lazer (MMA, 2011c).

O turismo com foco nos ambientes naturais começa a ser difundido no mundo com a Revolução Industrial, onde lugares de grande beleza cênica passaram a ser requisitados para que as populações urbano-industriais pudessem "refazer as energias gastas na vida estressante das cidades" (DIEGUES, 2001, p.13). O Parque de Yellowstone foi o primeiro a ser criado no mundo com este propósito, em 1872, nos Estados Unidos (DIEGUES, 2001).

Se o turismo em áreas protegidas por um lado ainda suscita polêmica quanto aos riscos que pode oferecer à biodiversidade em decorrência dos impactos que gera, por outro, em muitos países tem se convertido numa maneira de assegurar a conservação da natureza graças aos recursos financeiros gerados pelos visitantes (EAGLES et a.l, 2002; SWARBROOKE, 2002). Um estudo realizado em 118 áreas protegidas de 12 países da América Latina mostrou que em $36 \%$ dos casos a visitação gerava $30 \%$ ou mais do orçamento das áreas, sendo que para $12 \%$ delas a receita obtida com os ingressos constituía a única fonte de financiamento (TACÓN; FIRMANI, 2004). No Parque Nacional de Galápagos (Equador), em 1999, a receita advinda da visitação somou mais de US\$ 5 milhões, enquanto o orçamento no mesmo ano foi de US\$2,29 milhões (TAKAHASHI, 2004).

Em alguns países, nas últimas décadas, é notado o crescimento no número de visitantes que procuram atividades de lazer em áreas protegidas. Nos Estados Unidos, o National Park Service (NPS), órgão governamental que administra mais de 400 parques nacionais, registrou em 2016 aproximadamente 331 milhões de visitantes (NATIONAL PARK SERVICE, 2017). Na Austrália, somente os parques de Queensland recebem por ano mais de 51 milhões de visitas domésticas e 7,9 milhões de visitas internacionais (STATE OF QUEENSLAND, 2013). Na África do Sul, o South African National Parks (SANParks) registrou entre 2014 e 2015 mais de 1,6 milhão de visitantes apenas no Kruger National Park, o maior e mais antigo parque nacional africano (ENVIRONMENTAL AFFAIRS, 2015). Também no Brasil a receita de visitação em 2015 apresentou um aumento de $R \$ 22,4$ 
milhões em relação ao ano anterior, sendo que percentualmente o aumento foi de 39,64\%, com arrecadação total de $R \$ 56,6$ milhões (ICMBIO, 2016).

Este trabalho teve como objetivo geral examinar o tratamento que é dispensado aos programas de uso público em Parques Estaduais do Rio Grande do Sul. Como objetivos específicos, o estudo comparou o conteúdo dos programas de uso público com o que de fato vem sendo executado neste sentido. Objetivou também conhecer os principais entraves que interferem na implementação dos programas de uso público nos parques estaduais gaúchos, identificando qual a percepção que os gestores têm sobre esses programas.

\section{Método}

Foram selecionadas para o estudo as unidades de conservação estaduais do Rio Grande do Sul pertencentes à categoria Parque e, entre elas, aquelas que já possuem Plano de Manejo (Figura 1, próxima página).

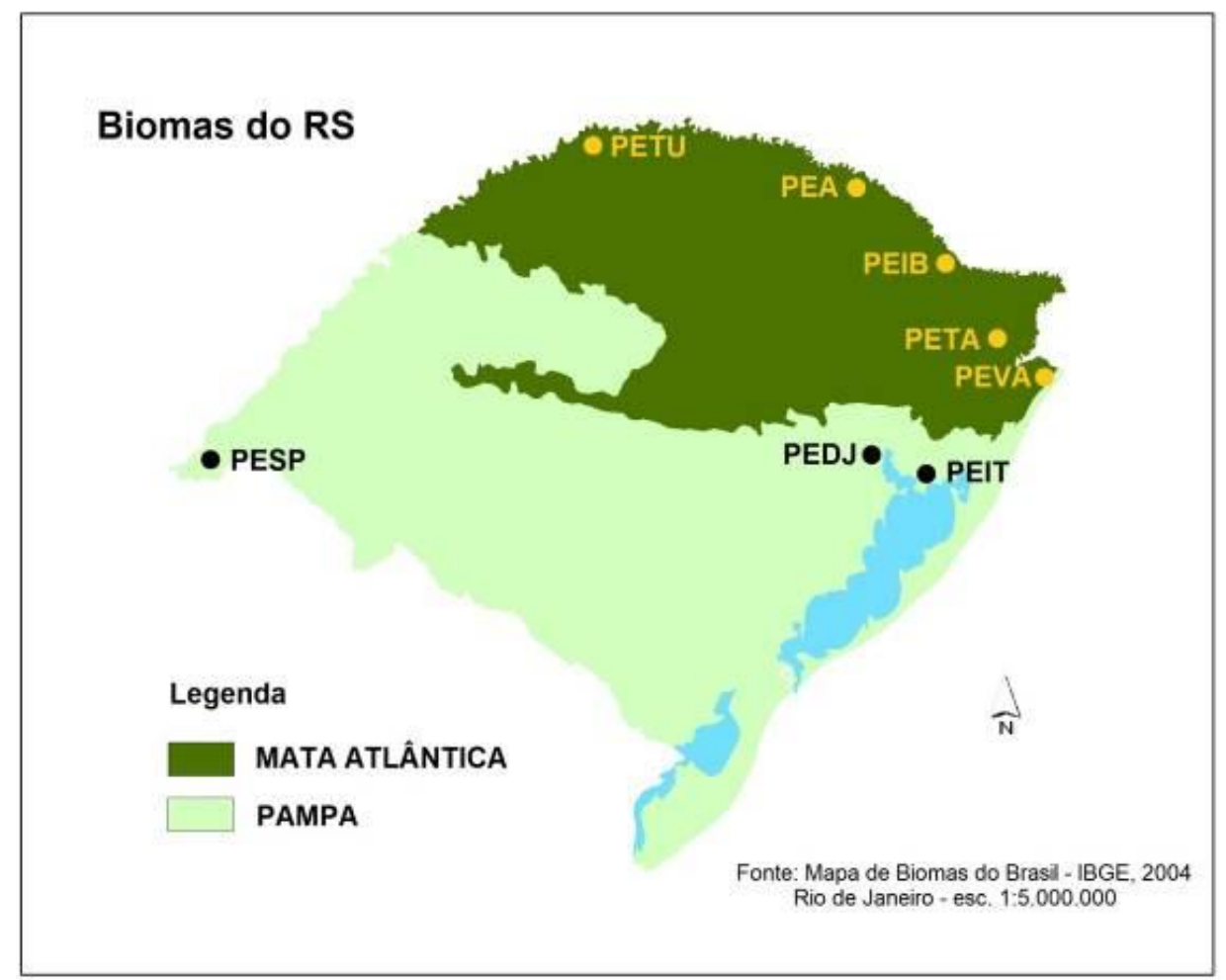

Figura 1: Localização dos Parques Estaduais do Rio Grande do Sul (biomas Mata Atlântica e Pampa) que possuem Plano de Manejo e que foram objeto de estudo quanto aos

Programas de Uso Público: PEDJ = Parque Estadual do Delta do Jacuí; PEA = Parque Estadual de Espigão Alto; PESP = Parque Estadual do Espinilho; $\mathrm{PEIB}=$ Parque Estadual do lbitiriá; PEIT = Parque Estadual de Itapuã; PETA = Parque Estadual do Tainhas; PETU = Parque Estadual do Turvo; e PEVA = Parque Estadual de Itapeva.

Fonte: Adaptado de Mapa de Biomas do Brasil - IBGE, 2004.

Figure 1: Location of State Parks of Rio Grande do Sul (Atlantic Forest and Pampa biomes) that have a management plan and were studied about the Use Public Program: PEDJ =

State Park of Delta do Jacuí; PEA = State Park of Espigão Alto; PESP = State Park of Espinilho; PEIB = State Park of Ibitiriá; PEIT = State Park of Itapuã; PETA = State Park of Tainhas; PETU = State Park of Turvo; and PEVA = State Park of Itapeva.

Source: Adapted from Brazilian Biomes Map - IBGE, 2004. 
Todos os planos de manejo foram consultados tendo como foco principal os capítulos relacionados ao uso público. A partir disso foi produzido um questionário semiestruturado, com 17 questões (Apêndice A), que foi aplicado aos gestores destas UC, entre os meses de agosto e outubro de 2016. A partir dos resultados obtidos com os questionários foi possível constatar o quanto dos programas de uso público foram ou estavam sendo executados, assim como conhecer a percepção de cada gestor sobre este tema

As respostas foram sistematizadas em planilha Excel permitindo a tabulação e interpretação dos resultados. Neste trabalho, quando é empregada a expressão "áreas protegidas" está se referindo exclusivamente a unidades de conservação, conforme as categorias previstas na lei que instituiu o Sistema Nacional de Unidades de Conservação (BRASIL, 2000).

\section{Resultados}

O Rio Grande do Sul conta com 23 Unidades de Conservação estaduais (3 Áreas de Proteção Ambiental, 1 Estação Ecológica, 1 Refúgio de Vida Silvestre, 6 Reservas Biológicas e 12 Parques Estaduais), sendo que entre os 12 Parques, oito contam com Planos de Manejo e representam as UC que fizeram parte deste estudo.

Dos oito parques investigados, apenas um se encontrava efetivamente aberto à visitação (Parque Estadual do Turvo) no momento do estudo e, mesmo assim, no entendimento de seu gestor, fatores internos (falta de estruturas) e externos (cheias do rio Uruguai e a presença das hidrelétricas) fazem com que a unidade não atenda plenamente a expectativa do visitante.

Seis parques (Delta do Jacuí, Espigão Alto, Espinilho, Ibitiriá, Itapeva e Tainhas) estavam fechados para a visitação, porém eventualmente recebiam grupos de escolares com o propósito específico de práticas de educação ambiental formal. O Parque Estadual de Itapuã, uma das mais emblemáticas unidades de conservação do Estado, criado em 1991 a partir de forte mobilização social contra a exploração de pedreiras (mineração de granito), desmatamento e invasão de construções nas suas praias, esteve fechado para visitação durante todo o ano de 2016, tendo sido reaberto no início de 2017 (após a conclusão deste estudo), porém de forma precária.

A falta de pessoal é apontada por todos os gestores como sendo o fator responsável pelo fato de sete parques estaduais não receberem visitantes. O parque que apresenta um quadro suficiente de funcionários que pode se envolver com as atividades de uso público é o do Turvo, o único aberto à visitação dentre os pesquisados. Cinco gestores também atribuem à carência de infraestrutura o principal motivo pelo qual não podem receber turistas.

A necessidade de capacitação de pessoal para atuar junto aos visitantes não aparece com prioridade nos planos de manejo. Mesmo no Parque Estadual do Turvo, o único aberto à visitação e com quadro de pessoal considerado suficiente, os funcionários não receberam capacitação 
específica. Treinamento para servidores, com este propósito, é previsto apenas em três programas de uso público. Até novembro de 2016, a única iniciativa de capacitação foi sediada no Parque Estadual de Itapuã, mas foi direcionada aos guardas-parque de toda a rede estadual. A formação não focou exclusivamente no atendimento ao público embora tenha abordado questões relacionadas. Antes disso, em 2013, moradores do entorno do Parque Estadual de Itapuã participaram de um curso de condutores ministrado pelo Instituto Federal de Educação, Ciência e Tecnologia do Rio Grande do Sul através do Programa Nacional de Acesso ao Ensino Técnico e Emprego (Pronatec). Apenas a partir do segundo semestre de 2016 os condutores formados em Itapuã tiveram condições de trabalhar.

Os questionários revelaram também que é grande o desconhecimento dos gestores quanto às normativas que dizem respeito à visitação em unidades de conservação. Apenas três gestores admitiram conhecê-las, sendo que entre as normativas está a Instrução (IN) SEMA 01/2014 que trata do aproveitamento de condutores no atendimento aos visitantes, documento produzido justamente no órgão ao qual ele está vinculado.

A previsão de implantação de trilhas interpretativas e edificações voltadas para 0 atendimento dos visitantes foram duas demandas encontradas nos oito parques investigados. Porém, apenas dois parques conseguiram implantar a totalidade das trilhas previstas. Nos demais estas lacunas permanecem sem previsão de atendimento, o que numericamente significa pelo menos dez trilhas não implantadas em um total de vinte e cinco previstas. Da mesma forma, as estruturas de recepção de visitantes (centro de visitantes, centro de interpretação ambiental ou museu) só se encontram totalmente instaladas em dois parques (Itapuã e Turvo) e parcialmente em um deles (Delta do Jacuí). Apenas o Parque Estadual de Espigão Alto conseguiu implantar na totalidade um sistema de sinalização para 0 visitante.

A necessidade de delimitar área destinada ao campismo está presente em três programas de uso público, porém até o encerramento deste trabalho os espaços voltados a esta atividade não estavam definidos na prática. Nos parques de Itapeva e de Itapuã já houve área para camping, mas os gestores alegam que faltam recursos para a manutenção da infraestrutura. Outras instalações de apoio ao uso público como guaritas, postos de vigilância, mirantes, torres de observação, pórticos e arboreto também tiveram baixo percentual de implantação, com apenas $22,2 \%$ realizado, isso considerando tudo o que estava previsto para ser executado nas oito UC.

Ainda sobre os compromissos assumidos pelos planos de manejo figuram como ações recorrentes e com interface no uso público a produção de materiais educativos - prevista para sete parques - e a realização de palestras nas escolas do entorno da UC - assumida para cinco deles. Por outro lado, a capacitação de pessoal para atuar nas atividades de uso público, o incentivo à economia local através do ecoturismo e 0 monitoramento de impactos advindos da visitação só aparecem em três planos de manejo. 
Nenhum dos parques estudados possui recursos financeiros específicos para uso público em seu orçamento, o que no entendimento da maioria dos gestores acaba também interferindo para que não haja visitação. A grande maioria dos recursos destinados aos parques e que chegam com esta finalidade provêm de compensações ambientais. Ocorre que tais recursos, segundo os gestores, são empregados principalmente na produção de material gráfico voltado à educação/informação/divulgação da UC.

A totalidade dos gestores vê o uso público como um aspecto positivo para a boa gestão. Sete concordaram que o uso público em parques deve ter a mesma atenção que se dispensa para as atividades relacionadas com a conservação dos ecossistemas naturais. Quatro gestores entendem que o fato de suas unidades estarem fechadas à visitação traz prejuízos não só para a UC como para as comunidades do entorno. No entendimento dos gestores, com a ausência de visitantes se perde a oportunidade de ampliar o conhecimento da sociedade sobre os valores da biodiversidade. Eles destacam também que, por não contar com a visitação, estes territórios deixam de contribuir com o desenvolvimento das comunidades do entorno. Embora apontando aspectos positivos da visitação, alguns gestores também enxergam impactos negativos por conta da presença dos turistas. No entanto, caso os oito parques tivessem visitação plena, somente em três deles seria possível gerar informações sobre os impactos da visitação, eis que monitoramento com este propósito não foi previsto para os demais.

O tempo de permanência no cargo de gestor nos oito parques aqui estudados é variado. Três gestores estavam na chefia há menos de três anos, um há menos de seis anos e três há menos de nove anos. Apenas um deles se encontra na chefia faz mais de dez anos, sendo que este foi o único gestor que já estava dirigindo a UC quando da elaboração do Plano de Manejo.

Pelo menos cinco gestores admitiram lacunas no programa de uso público da sua unidade. Ao mesmo tempo, quando solicitados a atribuírem uma nota de 0 a 10 para o parque que dirigem, considerando o potencial de visitação (tendo o zero como o baixíssimo potencial e o dez como máximo potencial), sete deles atribuíram notas acima de sete, considerando, portanto, que viam no parque que dirigem importantes atributos capazes de atrair turistas.

\section{Discussão}

A falta de esforço governamental para viabilizar/incrementar o uso público nos parques estaduais do Rio Grande do Sul é facilmente percebida neste trabalho. Cabe ao Estado a iniciativa de estabelecer diretrizes para o uso público, entretanto, a previsão de planos para essa finalidade só aparece nos programas de quatro dos oito parques estaduais estudados.

Os parques estaduais que fizeram parte do estudo não estão cumprindo integralmente com seus objetivos na medida em que não propiciam a visitação, recreação em contato com a natureza e o turismo ecológico de acordo com o que prevê a legislação (BRASIL, 2000). Quando 
os parques não atendem estes aspectos que fazem parte da essência de seu conceito, eles se aproximam de categorias mais restritivas - Estações Ecológicas e Reservas Biológicas - deturpando os propósitos da existência da categoria e, ao mesmo tempo, gerando uma lacuna no sistema de unidades de conservação que deixa de contar com unidades voltadas ao contato mais direto com a sociedade.

O estudo mostrou que o uso público no âmbito da gestão dos parques estaduais no Rio Grande do Sul não foge a regra e, quando ele está presente, mesmo assim é tratado como prática esporádica de atividades de educação ambiental, tal como já foi identificado por Pires e Faria (2015). Os autores destacam que o ideal seria que a educação e a interpretação ambiental fossem elementos que constituíssem os programas de uso público, que seriam integradores das ações voltadas à compreensão da importância das áreas protegidas. Corroborando com esse panorama, Canto-Silva et al. (2015b), em estudo sobre as ações de educação ambiental em 14 unidades de conservação pertencentes ao Sistema Estadual de Unidades de Conservação do Rio Grande do Sul, constataram que estas ocorrem de forma pontual, com pouco planejamento e sem objetivos claros relacionados ao compartilhamento da temática ambiental com a sociedade. Estes autores registraram, ainda, que a falta de estrutura das UC (como espaço físico, material didático, etc.) e a limitação de pessoal (equipe insuficiente e sem capacitação especifica) são as principais dificuldades enfrentadas pelos gestores para a realização das ações educativas.

O uso público não é um privilégio que o estado concede à população, mas sim um direito previsto no SNUC e uma importante ferramenta de manejo (MENEZES, 2014). O sistema atual de gestão de áreas protegidas deve reconhecer que a dimensão humana tem importância no desenvolvimento de qualquer estratégia para que a conservação alcance seus objetivos (PIRES \& FARIA, 2015). Não foi observado este tipo de entendimento quando do desenvolvimento da pesquisa, indicando que, pelo menos entre os parques estudados, a dimensão humana na gestão daquelas áreas ainda é pouco explorada.

A falta de funcionários para atender os visitantes é vista como o principal entrave para implementar 0 uso público. Em algumas oportunidades os gestores se amparam nos guardas-parques, mas estes também se apresentam em número reduzido nas unidades de conservação e precisam se envolver com as atividades de vigilância, patrulhamento e fiscalização contra a caça e pesca furtiva, principalmente. O Ministério do Meio Ambiente diagnosticou, em 2004, que nos parques estaduais do país, as atividades de uso público ocorrem principalmente com a presença de guardas-parques. Porém, os guardas-parques, mesmo quando treinados para atendimento ao público, enfrentam dificuldades na realização destas tarefas que precisam ser somadas a outras ligadas ao controle da UC (MMA, 2015a). No Parque Estadual do Tainhas, por exemplo, um guarda-parque precisa cobrir uma área de 6,65 mil hectares; no Parque Estadual do Espinilho, onde trabalhava apenas a gestora quando da realização deste estudo, a funcionária tinha que controlar mais de 1,6 mil hectares. Para fins de comparação, na África do Sul os guardas-parques controlam em média 
1,17 mil hectares e no Brasil esse número alcança 18,6 mil hectares (MEDEIROS et al., 2011).

Ainda em relação à falta de pessoal para desenvolver as atividades de uso público, cabe observar que apenas três gestores possuem conhecimento da Instrução Normativa SEMA 01/2014, que estabelece normas e procedimentos para a prestação de serviços relacionados à visitação e ao turismo em Unidades de Conservação de responsabilidade do Rio Grande do Sul por condutores ambientais autônomos. O estado do Rio Grande do Sul é uma das poucas unidades federativas brasileiras que apresentam bases legais sobre o tema em seus sistemas estaduais de unidades conservação (NASCIMENTO et al., 2016)

O condutor de visitantes ou condutor ambiental autônomo é o profissional capacitado para guiar visitantes dentro de áreas protegidas, principalmente em trilhas interpretativas (MTUR, 2010; BRASIL, 2014). Esse profissional, que normalmente vive dentro ou próximo da área protegida visitada, sendo por isso também denominado condutor ambiental local (CANTO-SILVA et al., 2015a), está habilitado a participar também do manejo e monitoramento da unidade de conservação (MTUR, 2011; RIO GRANDE DO SUL, 2014). Segundo Canto-Silva e Silva (2017), os condutores locais têm um papel protagonista na condução de visitantes nos Parques brasileiros, o que é muito pertinente para o desenvolvimento de um turismo ecológico nessas áreas, uma vez que isso contribui para a satisfação das necessidades socioeconômicas das regiões receptoras. Por outro lado, tal realidade contribui para a quebra de paradigmas excludentes, ao adotar a estratégia de agregar os saberes e fazeres dos moradores das áreas de entorno dessas áreas protegidas (CANTO-SILVA et al., 2015a). Como exemplo, um estudo para o Plano de Negócios do Parque Estadual do Itacolomi, MG, sugeriu a criação de uma associação de condutores do Parque para o desenvolvimento do uso público. A inspiração foi o Parque Nacional da Chapada dos Veadeiros, onde as visitas são guiadas por condutores pertencentes a uma associação (BURKOWSKI; VARAJÃO, 2010). Apesar deste panorama, tal realidade ainda é pouco entendida pelos órgãos ambientais do Rio Grande do Sul ligados ao planejamento e gestão das áreas protegidas.

Outra alternativa para enfrentar a falta de funcionários tem sido as parcerias com instituições de ensino. Neste caso, alunos atuando como estagiários podem ampliar os recursos humanos enquanto têm uma oportunidade de aprimorarem suas formações com atividades práticas (BURKOWSKI; VARAJÃO, 2010; MMA, 2015b). Existe ainda, através do Ministério do Meio Ambiente, o Programa de Voluntariado em Unidades de Conservação, instituído pela Portaria 19/05. O Programa pode ser implantado em qualquer unidade de conservação federal, estadual ou municipal. O objetivo é propiciar que os voluntários atuem com educação, interpretação ambiental e conscientização da sociedade (BRASIL, 2005). Então, ao que parece, o argumento que se apoia na falta de pessoal para não implementar o uso público nas UC estaduais pode ser enfraquecido se consideradas todas as alternativas existentes, mas que ainda não foram experimentadas no Rio Grande do Sul. 
Seguidas da falta de pessoal, as estruturas físicas de apoio ao uso público são citadas pela quase totalidade dos gestores como insuficientes. No Parque Estadual de Ibitiriá, por exemplo, não há nenhuma edificação e nos parques de Espigão Alto e do Tainhas os prédios existentes não foram concebidos para receber visitantes. Pires et al. (2014) constatam que a existência de estruturas físicas é uma pré-condição para viabilizar o uso público. A infraestrutura nos parques tem por objetivo expandir as oportunidades e a capacidade do turismo, sustentar a segurança e o bemestar do visitante, dar suporte à manutenção da integridade ecológica e satisfazer as necessidades da equipe do parque (EAGLES; MCCOOL, 2002 apud HIRATA, 2013).

No Parque Estadual de Campos do Jordão, SP, Hirata (2013) constatou que as demandas manifestadas por infraestruturas superam aquelas relacionadas por maior número de funcionários. Ao mesmo tempo, Pires et al. (2014, p.2) presumem que "não sendo a falta de atributos naturais e paisagísticos existentes nos parques de Santa Catarina", o motivo pelo qual a maioria dos parques não se encontrar dentre os destinos turísticos está a deficiente estrutura física e a falta de funcionários. Por outro lado, o Parque Estadual Morro do Diabo (SP) registrou em um ano aumento de $150 \%$ no número de visitantes e, em seis anos, $600 \%$, a partir do momento que passou a oferecer melhorias nas infraestruturas e cooperação com instituições de ensino, além do aumento no número de funcionários (PIRES; FARIA, 2015). Como estruturas físicas, Pires et al. (2014) relacionam os centros de visitantes, trilhas, caminhos, acessos, mirantes, áreas de camping e sinalização, entre outras.

Os impactos positivos advindos da visitação são percebidos por todos os gestores, entretanto, desses, quatro também reconhecem que a atividade pode trazer impactos negativos, dependendo do planejamento e das ações adotadas. Olsder e van der Donk (2006) já haviam mencionado que o turismo traz contribuições positivas para a conservação da biodiversidade quando a atividade é planejada, manejada e monitorada regularmente; quando isso não ocorre, os impactos negativos do turismo são evidentes. Os impactos considerados negativos decorrentes do uso público podem surgir tanto da presença dos visitantes quanto da construção de infraestrutura, tais como abertura de trilhas e edificações, cuja localização exata deve ser estudada de maneira criteriosa a fim de minimizar os danos (TACÓN; FIRMANI, 2004). Neste estudo os gestores identificaram como um impacto positivo decorrente da presença de visitantes a oportunidade de conscientizar o turista e provocar a reflexão sobre os valores ambientais, aspectos estes destacados em publicações oficiais (MMA, 2011a; MMA, 2015a). Como impactos negativos, reconhecem-se perturbações na fauna devido a atropelamentos e aos ruídos provocados pelos visitantes, bem como a disposição inadequada de resíduos. Os impactos negativos podem ser resultado do comportamento dos visitantes ou da falta de planejamento, que passa quando há esgotamento da capacidade de carga ou má distribuição de visitantes na área (TAKAHASHI, 1998; SANTOS JUNIOR; PIRES, 2008). Nos parques estaduais do RS estudados, o monitoramento dos impactos provenientes da visitação é previsto para sete deles, porém, 
para quatro tal processo é tratado de forma genérica, sem metodologia específica definida. Em três parques está estabelecido o método Manejo de Impacto da Visitação (MIV/VIM, em inglês), mas que ainda não foi aplicado. Esta técnica prevê a identificação dos impactos provenientes da visitação, suas causas e as soluções mais adequadas para enfrentá-los (COSTA \& MELLO, 2005). Correa e Abessa (2013), ao utilizarem esta metodologia em uma trilha no Parque Estadual Xixová-Japuí (SP), puderam concluir que os impactos negativos observados estariam mais relacionados à falta de planejamento e manutenção da mesma, somados a intempéries, do que à pressão direta da visitação.

Em relação ao potencial de visitação, os gestores consultados, em sua maioria, atribuíram boas notas aos parques que gerenciam. Entretanto, para que os parques desenvolvam integralmente sua capacidade de receber visitantes, necessitam estar integrados ao desenvolvimento local e aos patrimônios da região (RODRIGUES, 2008). Neste estudo, constatou-se que mais da metade dos parques pesquisados prevê alguma forma de envolvimento da comunidade local no uso público das unidades, porém esta iniciativa ainda permanece no campo das intenções. Os parques estaduais gaúchos possuem seus potenciais de visitação restritos aos atributos naturais encontrados dentro da própria UC. Pode-se dizer que os parques estudados não "conversam" com seu entorno e, portanto, não consideram no seu planejamento a vizinhança. Também não contam com parcerias com órgãos públicos e instituições privadas, o que poderia resultar na sua inserção em rotas turísticas e na promoção do desenvolvimento econômico local. Quanto mais variadas forem as ofertas, mais rico torna-se um destino, e é a partir do mapeamento de oportunidades que se consegue agregar valor para a visitação e alcançar benefícios mútuos.

\section{Conclusões}

Os Parques Estaduais do Rio Grande do Sul, no que se refere ao uso público, não estão cumprindo integralmente com os objetivos de sua categoria. Muitas das ações previstas nos programas de uso público estão restritas às esparsas ações de educação ambiental.

Mais da metade das ações propostas nos programas de uso público dos parques estudados não foram implantadas. Ao que parece, os programas de uso público são produzidos apenas para cumprir exigências legais e acabam não sendo utilizados como ferramenta de planejamento.

A insuficiência de funcionários é a principal queixa dos gestores para justificar a ausência de visitação ou uso público, seguida da falta de estruturas de apoio à visitação. Os Parques Estaduais do Espinilho, de Ibitiriá e do Tainhas são os que apresentam a situação mais crítica em relação às carências de infraestruturas e corpo técnico. Por outro lado, não são aproveitadas as alternativas que existem para suprir algumas carências de mão-de-obra.

Os programas de uso público possuem singularidades que, se por um lado permitem que a visitação seja realizada conforme as particularidades da 
UC, por outro dificultam a ordenação do turismo. Da mesma forma, a inexistência de diretrizes para a avaliação da eficácia das ações não permite compreender se os objetivos dos programas de uso público estão sendo alcançados, prejudicando sua posterior revisão.

Com base no levantamento do cenário do uso público em oito parques estaduais do Rio Grande do Sul, sugerem-se iniciativas que poderiam qualificar o atendimento ao visitante:

a)providenciar capacitação entre gestores atuais e potenciais do quadro de servidores, destacando os objetivos da categoria "parque" e inserindo a variável humana nas reflexões e diretrizes de gestão;

b)produzir diretrizes, regulamentações, normativas ou roteiros metodológicos, que orientem o planejamento, desenvolvimento e avaliação do uso público nas UC do estado do Rio Grande do Sul;

c)estabelecer cooperação com instituições de ensino e organizações não governamentais para suprir a carência de recursos humanos através de estagiários ou bolsistas;

d)iniciar a discussão sobre o melhor aproveitamento turístico dos parques, considerando a possibilidade da concessão de espaços e serviços para receber o visitante e gerar receita;

e)estabelecer acordos com órgãos públicos municipais e regionais para divulgação e inserção dos parques em rotas turísticas, promovendo o desenvolvimento local a partir do uso público.

Por fim, espera-se que os resultados desse trabalho possam contribuir com as soluções que venham a ser buscadas para suprir as lacunas que impedem uma melhor relação entre os parques estaduais e o público interessado em conhecer estes valores ambientais.

\section{Referências}

BRASIL. Lei no 9985, de 18 de junho de 2000. Regulamenta o art. 225, $\S 1$, incisos I, II, III, e VII da Constituição Federal, institui o Sistema Nacional de Unidades de Conservação da Natureza e dá outras providências. Diário Oficial da República Federativa do Brasil, Brasília, DF, 19 jul. 2000. Disponível em: http://pesquisa.in.gov.br/imprensa/jsp/visualiza/index.jsp?jornal=1\&pagina=45\&d ata=19/07/2000. Acesso em: 27 jul. 2017

BRASIL. Portaria Ministério do Meio Ambiente no 19, de 21 de janeiro de 2005. Dispõe sobre a criação do Programa de Voluntariado em Unidades de Conservação. Diário Oficial da República Federativa do Brasil, Brasília, DF, 24 jan. $2005 . \quad$ Disponível em: http://pesquisa.in.gov.br/imprensa/jsp/visualiza/index.jsp?jornal=1\&pagina=103\& data=24/01/2005. Acesso em: 28 jul. 2017.

BRASIL.Portaria do Ministério do Turismo nำ27, de 30 de janeiro de 2014. Estabelece requisitos e critérios para o exercício da atividade de Guia de Turismo e dá outras providências. Diário Oficial da República Federativa do Brasil, Brasília, DF, 31 jan. 2014. Disponível em http://www.turismo.gov.br/legislacao/?p=117. Acesso em: 07 jul. 2017. 
BURKOWSKI, R.; VARAJÃO, G.F.D.C. Sustentabilidade da Visitação Pública em Unidades De Conservação: um estudo de caso do Plano de Negócios do Parque Estadual Do Itacolomi-MG. Caderno de Geografia, Belo Horizonte: v.20, n.34, 22p, jul. - dez. 2010. Disponível em: $<$ http://periodicos.pucminas.br/index.php/geografia/article/view/1663/1770>.

Acesso em: 26 jul. 2017.

CANTO-SILVA, C.R.; SILVA, J.S. Panorama da visitação e da condução de visitantes em Parques brasileiros. Revista Brasileira de Pesquisa em Turismo, São Paulo: v.11, n.2, p. 365-386, mai-ago, 2017. Disponível em: https://dx.doi.org/10.7784/rbtur.v11i2.1286. Acesso em 15 ago. 2017.

CANTO-SILVA, C.R.; CUNHA, A.M.; BAZOTTI, L.S.; NASCIMENTO, C.A. Formação e Organização de Condutores Ambientais Locais: Estratégias de Desenvolvimento do Turismo Sustentável em Unidades de Conservação Gaúchas. Anais do Seminário Brasileiro sobre Áreas Protegidas e Inclusão Social, 7., 2015a, Florianópolis. Florianópolis: UFSC, 2015a. p. 211-219.

CANTO-SILVA, C.R.; LOKSCHIN, L.X.; NASCIMENTO, C.A.; VELHO, L.F.; SILVA, S.L.C.; BJERK, R.L. Educação Ambiental em Unidades de Conservação Gaúchas In: LAZZARI, C.; SEHNEM, C.; CARDOSO, D.; CARVALHO, N. (Org.). Pesquisa e ensino: ferramentas de gestão pública no RS: coletânea de artigos do convênio FDRH e FAPERGS. Porto Alegre: Companhia Rio-grandense de Artes Gráficas (CORAG), 2015b. p. 66 - 92. Disponível em <http://www.fdrh.rs.gov.br/upload/1453310228 FDRH\%20ebook.pdf>. Acesso em 15 ago. 2017.

CORREA, K.M.; ABESSA, D.M.S. Estudo dos indicadores de impacto da visitação na Trilha dos Surfistas, Parque Estadual Xixová - Japuí (SP). Nature and Conservation, Aquidabã: v.6, n.2, mai-out, 2013.

COSTA, V.C.; MELLO, F.A.P. Manejo e monitoramento de trilhas interpretativas: contribuição metodológica para a percepção do espaço ecoturístico em unidades de conservação. In: Anais do Simpósio Nacional sobre Geografia, Percepção e Cognição do Meio Ambiente, 1, 2005, Londrina. Londrina: UEL, $2005 . \quad$ Disponível em: <https://geografiahumanista.files.wordpress.com/2009/11/vivian.pdf >.

Acesso em: 23 out. 2017.

DIEGUES, A.C.S. O Mito Moderno da Natureza Intocada. 3. ed. São Paulo: HUCITEC e NUPAUB, 2001. $161 \mathrm{p}$.

EAGLES, P.F.J.; MCCOOL, S.F.; HAYNES, C.D. Sustainable Tourism in Protected Areas: Guidelines for Planning and Management. [S.I.]: IUCN Gland, Switzerland and Cambridge. 2002. 191 p.

ENVIRONMENTAL AFFAIRS. Foreign visitor numbers to Kruger National Park on the rise in 2014/2015 financial year. Departament of Environmental Affairs. [S.I.], 24 mai. 2015.2 Disponível em: $<$ https://www.environment.gov.za/mediarelease/moreforeignvisitors krugernatio nalpark $>$. Acesso em: 26 jul. 2017.

FREITAS, W.K.; MAGALHÃES, L.M.S.; GUAPYASSÚ, M.S. Potencial de uso público do Parque Nacional da Tijuca. Acta Scientiarum. Technology, Maringá: v. 24, n.6, p. 1833 - 1842, 2002. 
HIRATA, S. R.. Gestão da visitação em Unidades de Conservação: o caso do Parque Estadual de Campos do Jordão, SP. 2013. 218f. Dissertação (Mestrado em Ciências). Programa Interunidades de Pós-Graduação em Ecologia Aplicada, Universidade de São Paulo, Piracicaba, 2013.

IBGE. Mapa de Biomas do Brasil. Rio de Janeiro, 2004. 1 mapa. Escala: 1:5.000.000. Disponível em: http://www.biodiversidade.rs.gov.br/arquivos/1161807846biomas rs.jpg. Acesso em: 17 ago. 2017.

ICMBIO. Parque Nacional da Tijuca. s/d. Disponível em: http://www.icmbio.gov.br/parnatijuca/guia-do-visitante.html. Acesso em: 23 out. 2017

ICMBIO. Relatório de Gestão 2015. Brasília: Ministério do Meio Ambiente, 2016, 120p. Disponível em: $<$ http://www.icmbio.gov.br/acessoainformacao/images/stories/relatorios/Relatori o de gestao 2015 INTERNET.pdf >. Acesso em: 26 jul. 2017.

ICMBIO. Dados de Visitação 2007 - 2016. 2017. Disponível em: $<$ http://www.icmbio.gov.br/portal/images/stories/comunicacao/noticias/2017/dad os de visitacao 2012 2016.pdf> . Acesso em: 25 jul. 2017.

INSTITUTO SEMEIA. Análise 2012 - Uso Público e Parcerias para Conservação e Desenvolvimento. [S.I.]: Instituto Semeia, 2012, 50 p. Disponível em: http://www.terrabrasilis.org.br/ecotecadigital/pdf/analise-2012uso-publico-e-parcerias-para-conservacao-e-desenvolvimento-a-perspectivados-gestores-de-unidades-de-conservacao-do-brasil.pdf. Acesso em 26 jul. 2017.

INSTITUTO SEMEIA. Diagnóstico do uso público em parques brasileiros: a perspectiva dos gestores. [S.I.]: Instituto Semeia, 2015. 118p. Disponível em: $<$ http://www.semeia.org.br/admuploads/uploads/download.php?doc=diagnostico do uso publico 2015 ALTA.pdf\&tp=3\&id=25>. Acesso em 26 jul. 2017.

MEDEIROS, R.; YOUNG; C.E.F.; PAVESE, H.B.; ARAÚJO, F.F.S. Contribuição das unidades de conservação brasileiras para a economia nacional: Sumário Executivo. Brasília: UNEP-WCMC, 2011, 44p. Disponível em:

$<$ http://www.icmbio.gov.br/portal/images/stories/comunicacao/estudocontribuica o.pdf>. Acesso em: 26 jul. 2017.

MENEZES, P.C. Conhecer para conservar. Um rápido olhar histórico seguido da verdadeira motivação do ecoturismo para todos que trabalham com conservação. In: BENSUSAN, N.; PRATES, A. P. (org.). A diversidade cabe na unidade?: áreas protegidas no Brasil. Brasília: IEB, 2014, p. 251-266.

MMA. Diagnóstico da visitação em parques nacionais e estaduais. Brasília: Ministério do Meio Ambiente, 2004, 51p. Disponível em: $<$ http://www.mma.gov.br/estruturas/sbs dap/ arquivos/diagnostico da visitacao em parques>. Acesso em: 26 jul. 2017.

MMA. Diretrizes para Visitação em Unidades de Conservação. Brasília: Ministério do Meio Ambiente, 2006. 65p. 
MMA. Diretrizes para Estratégia Nacional de Comunicação e Educação Ambiental em Unidades de Conservação - ENCEA. Brasília: Ministério do Meio Ambiente, 2011a, 48 p.

MMA. Revista sobre o Sistema Nacional de Unidades de Conservação da Natureza. Brasília: Ministério do Meio Ambiente, 2011b, 16p.

MMA. Roteiro metodológico de planejamento: Parque Nacional, Reserva Biológica, Estação Ecológica - Versão para discussão. Brasília: Ministério do Meio Ambiente, 2011c, 133 p.

MMA. O desafio de garantir participação no complexo universo da gestão. Brasília: Ministério do Meio Ambiente, 2015a, 66p. (Série Educação Ambiental e Comunicação em Unidades de Conservação).

MMA. Tornar-se visível: estratégia para promover articulações e captar recursos. Brasília: Ministério do Meio Ambiente, 2015b, 70p. (Série Educação Ambiental e Comunicação em Unidades de Conservação).

MTUR. Ecoturismo: orientações básicas. $2^{\underline{a}}$ edição. Brasília: Ministério do Turismo, 2010, 96p.

MTUR. Manual de orientações metodológicas: Fomento ao turismo em Parques Nacionais e entorno. Brasília: Ministério do Turismo, 2011, 78p. Disponível em: $<$ http://www.turismo.gov.br/sites/default/turismo/o ministerio/publicacoes/downlo ads publicacoes/Manual Orientacoes Metodologicas Fomento ao Turismo e m Parques e Entorno.pdf >. Acesso em: 28 jul. 2017.

NASCIMENTO, C.A.; CANTO-SILVA, C.R.; MELO, I.B.N.; MARQUES, S.C.M. A regulamentação da atividade de condução de visitantes nos Sistemas Estaduais de Unidades de Conservação do Brasil. Revista Brasileira de Pesquisa em Turismo, São Paulo, v. 10, n. 3, p. 516-532, set., - dez., 2016.

NATIONAL PARK SERVICE. Annual Visitation Highlights. Nps.gov. [S.I.], 6 jul. 2017. Disponível em: https://www.nps.gov/subjects/socialscience/annualvisitation-highlights.htm. Acesso em: 25 jul. 2017.

OLSDER, K.; VAN DER DONK, M. Destination Conservation: Protecting nature by developing tourism. Amsterdã: IUCN National Committee of the Netherlands , 2006, 95p.

PIRES, P.S.; SILVA, P.R.M.; LAMIM, G. A estruturação das Unidades de Conservação federais e estaduais da categoria "Parque" em Santa Catarina para o atendimento ao visitante. Anais do Seminário da Associação Nacional Pesquisa e Pós-Graduação em Turismo, 11., 2014, Fortaleza: UECE, 2014.

PIRES, A.S.; FARIA, H.H. Reestruturação do Programa de Uso Público e educação ambiental do Parque Estadual do Morro do Diabo (SP). Revista Brasileira de Educação Ambiental, São Paulo, v. 10, n. 3, p 200-220, 2015.

RIO GRANDE DO SUL (Estado). Instrução Normativa SEMA no 01 de 3 de janeiro de 2014. Estabelece normas e procedimentos para a prestação de serviços relacionados à visitação e ao turismo em Unidades de Conservação de responsabilidade do Estado do Rio Grande do Sul por condutores ambientais autônomos. Disponível em: $<$ http://www.servico.corag.com.br/diarioOficial/verJornal.php?pg=028\&jornal=do e\&dt=06-01-2014>. Acesso em: 27 jul. 2017. 
RODRIGUES, J.C. Geoturismo - uma abordagem emergente. In: CARVALHO, C. N.; RODRIGUES, J. C.; JACINTO, A. (org.). Geoturismo \& Desenvolvimento local. Idanha-a-Nova: Câmara Municipal de Idanha-a-Nova, 2008, p. 38-61. Disponível em: <www.naturtejo.com/ficheiros/conteudos/files/livro\%203(1).pdf >. Acesso em: 26 jul. 2017.

SANTOS JUNIOR, O.D.; PIRES, P.S. Turismo em Unidades de Conservação: adaptação do método Visitor Activity Management Process (VAMP) para a caracterização do uso público e o manejo de visitantes no Parque Estadual da Ilha do Mel (PR). Revista Hospitalidade, São Paulo, ano 5, n. 1, p. 59-79, jun. 2008.

SECRETARIAT OF THE CONVENTION ON BIOLOGICAL DIVERSITY. Guidelines on biodiversity and tourism development. Montreal: Secretariat of the convention on biological diversity, 2004, 34p. Disponível em: <https://www.cbd.int/doc/publications/tou-gdl-en.pdf>. Acesso em: 26 jul. 2017.

STATE OF QUEENSLAND. Queensland Ecotourism Plan 2013-2020. [S.I.]: Queensland Government, 2013, 21p. Disponível em: https://www.cabinet.qld.gov.au/documents/2013/aug/ecotourism\%20plan/Attach ments/Plan.PDF. Acesso em: 26 jul. 2017.

SWARBROOKE, J. Turismo sustentável: turismo cultural, ecoturismo e ética. São Paulo: Aleph, 2002. 358p. (Série Turismo Sustentável, v.5).

TACÓN, A; FIRMANI, C. Manual de senderos y uso público. Valdivia: CIPMA-FMAM, 2004, 24p. Disponível em: http://senderoslatinoamericanos.org/wpcontent/uploads/2013/11/manual de senderos y uso publico.pdf. Acesso em: 26 jul. 2017.

TAKAHASHI, L.Y. Caracterização dos visitantes, suas preferências e percepções e avaliação dos impactos da visitação pública em duas unidades de conservação do estado do Paraná. 1998. 144f. Tese (Doutorado em Ciências Florestais). Programa de Pós-Graduação em Engenharia Florestal, Universidade Federal do Paraná, Curitiba, 1998.

TAKAHASHI, L. Uso Público em unidades de conservação. Cadernos de Conservação, Curitiba, v. 2, n. 2, out. 2004.

Nota: Este artigo é resultado do trabalho de conclusão de curso desenvolvido pela primeira autora e orientado pelo segundo autor no Curso de Especialização em Gestão da Qualidade para o Meio Ambiente, pela Pontifícia Universidade Católica do Rio Grande do Sul.

Agradecimentos: Aos gestores dos Parques analisados pela disponibilidade em contribuir com a pesquisa. À Divisão de Unidades de Conservação da Secretaria Estadual do Ambiente e Desenvolvimento Sustentável pela autorização da pesquisa e pela disponibilização de informações para a elaboração do estudo. 
Izadora Flores Rech: Prefeitura Municipal de Eldorado do Sul, RS, Brasil. E-mail: izadora.rech@gmail.com Link para o currículo Lattes: http://lattes.cnpq.br/2536520732343205

Luís Fernando Carvalho Perello: Fundação Estadual de Proteção Ambiental Henrique Luís Roessler, Porto Alegre. RS, Brasil.

E-mail: Ifperello@yahoo.com.br

Link para o currículo Lattes: http://lattes.cnpq.br/7188124962880909

Celson Roberto Canto-Silva: Instituto Federal de Educação, Ciência e Tecnologia do Rio Grande do Sul, Porto Alegre, RS, Brasil.

E-mail: celson.silva@poa.ifrs.edu.br

Link para o currículo Lattes: http://lattes.cnpq.br/0403780115544325

Data de submissão: 05 de setembro de 2017

Data de recebimento de correções: 25 de outubro de 2017

Data do aceite: 25 de outubro de 2017

Avaliado anonimamente 


\section{APÊNDICE A - Questionário de percepção sobre o uso público aplicado aos gestores dos parques analisados}

1. Há quanto tempo você trabalha no Parque?

2.O entendimento que temos de uso público é o de processo que envolve o uso da Unidade de Conservação pelo público através de atividades turísticas, culturais, educativas, etc, promovendo o conhecimento do meio ambiente como um todo e principalmente do Sistema Nacional de Unidades de Conservação, situando a Unidade e seu entorno, de forma a prever ações no que diz respeito à recepção e atendimento ao visitante (MINISTÉRIO DE MEIO AMBIENTE, 2011). Você concorda com esse conceito?
( ) Sim ( ) Não

2.1.Se você respondeu "Não", conceitue seu entendimento de uso público:

3.O Parque está aberto à visitação?

\section{( ) Sim ( ) Não ( ) Apenas para EA e pesquisa}

4.Caso o Parque esteja aberto à visitação ou à educação ambiental/pesquisa científica, você acha que o Parque atende a expectativa do visitante?

( ) $\operatorname{Sim}$ ( ) Não

4.1.Se você respondeu "Não", aponte qual a razão pela qual você avalia que não atende a expectativa:

5.Caso o Parque não esteja aberto à visitação, qual a razão?

( ) Falta de pessoal ( ) Falta de estrutura física ( ) Recursos orçamentários insuficientes ( ) Outro motivo:

5.1.Caso o Parque não esteja aberto à visitação, você acha que isto pode trazer algum prejuízo para o Parque?

( ) Não ( ) Sim. De que forma?

5.2.Caso o Parque não esteja aberto à visitação, você acha que isto pode trazer algum prejuízo para a comunidade?

( ) Não ( ) Sim. De que forma?

6.Particularmente, você entende que o Uso Público num Parque é um Programa ou Ação de cunho imprescindível para a política de gestão das UC do estado?

( ) $\operatorname{Sim}($ ) Não

7.Você acredita que o desenvolvimento do Uso Público em um Parque é mais importante que a preservação de ecossistemas naturais?
( ) Sim, eu acredito ( ) Não, eu não acredito
a mesma importância em um Parque
( ) Eu acredito que ambos possuem

8. Você acredita que o Uso Público traz, para a Unidade de Conservação, impactos:
( ) Negativos
( ) Positivos
( ) Não traz nenhum impacto

9.Dentre as suas atribuições como gestor, aquelas relacionadas com o Uso Público você classificaria como (múltipla escolha):
( ) Estressantes
( ) Prazerosas
( ) Importantes conservação
( ) Positivas para a conservação
( ) Outra:
( ) Negativas para a

10.Com exceção do Parque que gerencia, quais outras Unidades de Conservação você conhece?

11.Comparando o Parque onde você trabalha com outros parques, em uma escala de 0 (péssimo) a 10 (ótimo), que nota você daria para o Parque que gerencia em relação ao potencial de visitação:
( )1
( )2
( ) 3
( )4
( )5 ( )6
( ) 7
( )8
( ) 9 ( )10 
12.Como você avalia as estruturas de apoio ao uso público no Parque:

a)( ) Encontram-se em número suficiente e em bom estado de conservação

b)( ) Encontram-se em número suficiente, entretanto, em mau estado de conservação

c)( ) Encontram-se em número insuficiente, entretanto, em bom estado de conservação

d)( ) Encontram-se em número insuficiente e em mau estado de conservação

12.1. Caso você tenha respondido a alternativa "b" ou "c" ou "d", você acredita que isso interfere no número atual de visitantes do Parque?

\section{( ) Sim ( ) Não}

13.Como você avalia o quadro de pessoal do Parque relacionado ao uso público:

a)( ) Encontram-se em número suficiente e em capacitação contínua

b)( ) Encontram-se em número suficiente, entretanto, sem capacitação contínua

c)( ) Encontram-se em número insuficiente, entretanto, em capacitação contínua

d)( ) Encontram-se em número insuficiente e sem capacitação contínua

13.1. Caso você tenha respondido a alternativa "b" ou "c" ou "d", você acredita que isso interfere no número atual de visitantes do Parque?

( ) $\operatorname{Sim}$ ( ) Não

14.O Parque possui recursos financeiros específicos para uso público em seu orçamento?

a)( ) Não, e não recebe recursos para o desenvolvimento de tais atividades

b)( ) Não, mas recebe recursos para o desenvolvimento de tais atividades através de compensação ambiental, etc.

c)( ) Sim, o Parque possui orçamento para uso público de forma sistemática, porém não suficiente

d)( ) Sim, o Parque possui orçamento para uso público de forma sistemática e suficiente

14.1. Caso você tenha respondido a alternativa "a" ou "b" ou "c", você acredita que isso interfere no número atual de visitantes do Parque?

( ) $\operatorname{Sim}$ ( ) Não

15.Você acredita que materiais de divulgação/informação/educação ao visitante são importantes para o alcance dos objetivos do Uso Público na UC?

( ) Sim ( ) Não

16. Você reconhece alguma lacuna no Programa de Uso Público do Parque que gerencia?

( ) Não ( ) Sim. Qual?

16.1. Caso tenha respondido "Sim", você sugeriria mudanças no Programa de Uso Público do Parque?

( ) Não ( ) Sim. Quais?

17.Você tem conhecimento de normativas ou regulamentações referentes à prestação de serviços relacionados à visitação e ao turismo nas Unidades de Conservação de responsabilidade do estado do RS?

( ) Não ( ) Sim. Qual? 